\title{
Pharmacokinetics of isoniazid, rifampicin, pyrazinamide and ethambutol in Indian children
}

\author{
Aparna Mukherjee ${ }^{1}$, Thirumurthy Velpandian², Mohit Singla, Kunwar Kanhiya ${ }^{2}$, Sushil K Kabra ${ }^{1}$ and Rakesh Lodha ${ }^{1 *}$
}

\begin{abstract}
Background: The available pharmacokinetic data on anti-tubercular drugs in children raises the concern of suboptimal plasma concentrations attained when doses extrapolated from adult studies are used. Also, there is lack of consensus regarding the effect of malnutrition on pharmacokinetics of anti-tubercular drugs in children. We conducted this study with the aims of determining the plasma concentrations of isoniazid, rifampicin, pyrazinamide and ethambutol achieved with different dosage of the anti-tubercular drugs so as to provide supportive evidence to the revised dosages and to evaluate the effects of malnutrition on the pharmacokinetics of these drugs in children. We also attempted to correlate the plasma concentrations of these drugs with clinical outcome of therapy.

Method: Prospective drug estimation study was conducted in two groups of children, age 6 months to 15 years, with tuberculosis, with or without severe malnutrition, receiving different dosage of daily anti- tubercular therapy. The dosage (range) of isoniazid was 5 (4-6) and 10 (7-15) $\mathrm{mg} / \mathrm{kg}$ in the two groups, respectively, that of rifampicin-10 (8-12) and $15(10-12) \mathrm{mg} / \mathrm{kg}$, respectively, both the groups received same dose of pyrazinamide (30-35 mg/kg) and ethambutol $(20-25 \mathrm{mg} / \mathrm{kg})$. All four drugs were simultaneously estimated by liquid chromatography-mass spectrometry (LC-MS/MS).

Results and conclusion: The median (IQR) $C_{\max }$ of isoniazid increased significantly from $0.6(0.3,1.2) \mu \mathrm{g} / \mathrm{mL}$ to 3.4 $(1.8,5.0) \mathrm{\mu g} / \mathrm{mL}$ with increase in the dose. Plasma rifampicin concentrations increased only marginally on increasing the dose [median (IQR) $C_{\text {max }}: 10.4(7.2,13.9) \mu \mathrm{g} / \mathrm{mL}$ vs. $\left.12.0(6.1,24.3) \mu \mathrm{g} / \mathrm{mL}, \mathrm{p}=0.08\right]$. For ethambutol, $55.9 \%$ of the children had inadequate 2-hour concentrations. Two-hour plasma concentrations of at least one drug were low in 59 (92.2\%) and 54 (85.7\%) children in the two dosing regimen, respectively. We did not observe any effect of malnutrition on pharmacokinetic parameters of the drugs studied. We did not observe an association between low plasma drug concentrations and poor outcome. We may have to be cautious while increasing the doses and strive to asses other factors influencing the drug concentrations and treatment outcomes in children.
\end{abstract}

Keywords: Tuberculosis, Children, Plasma concentrations, Anti-tubercular therapy, Malnutrition

\section{Background}

Escalating reports of treatment failure and emergence of resistance worldwide with the use of standard short course chemotherapy for tuberculosis (TB) reflect a worrying trend. In 2013, $20 \%$ of those previously treated for tuberculosis had multidrug resistance [1]. Subtherapeutic plasma concentrations of anti-tubercular drugs in adults have been implicated as one of the causes of treatment failure and emergence of resistance [2-5].

\footnotetext{
* Correspondence: rakesh_lodha@hotmail.com

${ }^{1}$ Department of Pediatrics, All India Institute of Medical Sciences, New Delhi, India

Full list of author information is available at the end of the article
}

The pharmacokinetic data on anti-tubercular drugs in children raises the concern of suboptimal plasma concentrations attained when the same $\mathrm{mg} / \mathrm{kg}$ dose used in adults is extrapolated to children [6-11]. Children absorb, metabolize and eliminate these drugs in a different manner than adults. It is extrapolation of adult doses to children, without correctly accounting for the changes in pharmacokinetics with growth and maturation, etc. that may lead to incorrect dosing in children. Though isoniazid has been studied extensively, there are relatively fewer studies on rifampicin, pyrazinamide and ethambutol in children. These studies vary in the type of assay used for measurement of drug concentrations, sampling schedule adopted, type of anti-tubercular therapy (ATT) 
administered-intermittent or daily and type of formulations used-fixed dose combination or separate single formulations. These variations make direct comparison of data obtained from the available pharmacokinetic studies in children challenging.

After a review of available data, WHO has recommended revision of the doses of isoniazid, rifampicin and pyrazinamide in children, with an intent to reach the usually recommended targets for adults [12].

Malnutrition is associated with various processes in the body which may influence the pharmacokinetics of the anti-tubercular drugs - malabsorption, as well as enteric infections, deranged drug metabolizing enzymes, alteration in the protein binding of drugs, an increased or decreased renal clearance, and changes in the body composition (lower fat and lean body mass) [13,14]. If patients absorb only portions of their drug regimen, effectively they are exposed to a regimen of fewer anti-tubercular drugs or even monotherapy leading to the selection of resistant strains [13-15]. The effect of malnutrition on pharmacokinetics of anti-tubercular drugs in children has not been very well explored. The few studies which are available lack consensus. In a recently published study, Ramachandran et al. reported on the pharmacokinetics of three anti-tubercular drugs in Indian children using intermittent regimen and observed that the drug concentrations were affected by age, malnutrition and INH acetylator phenotype [16]. This study was planned to assess the plasma concentrations of isoniazid (INH), rifampicin (RIF), pyrazinamide (PZA) and ethambutol (EMB) achieved in children. The effect of different doses on the drug concentrations was evaluated for RIF and INH, only; while the effect of malnutrition was explored for all 4 drugs. An attempt was also made to correlate plasma concentrations of the said drugs with clinical outcome of therapy.

\section{Methods}

This prospective study was carried out in a tertiary care hospital in New Delhi, India from 2009 to 2012. Children were screened and then enrolled from TB clinic services of the Department of Pediatrics, All India Institute of Medical Sciences, New Delhi. The study was approved by the Ethics Committee of the All India Institute of Medical Sciences. Written informed consent was taken from parents/guardians, assent was taken from children above seven years of age.

Children 6 months- 15 years age, who were newly diagnosed to have tuberculosis (pulmonary or extrapulmonary) and administered Category I ATT, were eligible for the study. Children with known HIV infection or any history, symptoms or signs suggestive of HIV infection, with poor general condition with high chances of mortality, known hepatic (transaminases $>5$ times the upper normal limit) or renal dysfunction (creatinine $>0.7 \mathrm{mg} / \mathrm{dL}$ ), adherence to $\mathrm{ATT}<80 \%$ in two weeks preceding the pharmacokinetic session, those with chronic diarrhea/ steatorrhea at the time of enrollment, and those with abdominal tuberculosis were excluded.

In the initial part of the study (2009-2011), children received the standard dosing schedule of ATT. Subsequently the second group was enrolled who received the revised dosing schedule of INH and RIF (Table 1). The national guidelines [17] were revised in favor of higher doses of isoniazid and rifampicin in 2012. However, even till date the same has not been operationalized. The enrollment in the standard dosing group was continued in view of the fact that data on Indian children generated from well-planned pharmacokinetic study were lacking and the findings of the current study would provide more robust evidence in support of these dose changes. Each of these groups had two subgroups: children without severe malnutrition and children with severe malnutrition. For the purpose of this study, severe malnutrition was defined in children upto five years of age as weight for height/ length $<70 \%$ of expected [expected being $50^{\text {th }}$ centile of CDC weight for height/length curve] and in children above five years as body mass index (BMI) for age $<5$ th percentile $[18,19]$. The definition of malnutrition that was used in clinical practice at the beginning of the study was used in the proposal and for sake of uniformity was not changed later on.

Diagnosis of tuberculosis was established according to the standard guidelines [20]. Confirmation of Mycobacterium tuberculosis by Ziehl Neelsen staining and MGIT$960^{\circ}$ culture system was attempted from any biological sample as feasible.

On enrollment a detailed history was taken, physical examination and anthropometric assessment (weight, height) were carried out.

\section{Treatment}

Category based anti-tubercular therapy as recommended by Revised National Tuberculosis Control Program (RNTCP) was administered [21], daily therapy was followed - four drugs (isoniazid, rifampicin, pyrazinamide and ethambutol) in intensive phase for first two months followed by two drugs (isoniazid and rifampicin) for four months during maintenance phase. This is considered as category I as per RNTCP. For children continuing to have clinical symptoms or radiological findings attributable to tuberculosis at the end of

\begin{tabular}{l} 
Table $\mathbf{1}$ Recommended doses of first-line anti-TB drugs \\
for children \\
\begin{tabular}{lll}
\hline Drugs & $\begin{array}{l}\text { Standard dose } \mathbf{( m g / k g ) ,} \\
\text { range (22) }\end{array}$ & $\begin{array}{l}\text { Revised dose } \mathbf{m g} / \mathbf{k g}), \\
\text { range (22) }\end{array}$ \\
\hline Isoniazid & $5(4-6)$ & $10(7-15)$ \\
Rifampicin & $10(8-12)$ & $15(10-20)$
\end{tabular} \\
\hline
\end{tabular}


2 months, the intensive phase was extended for another one month. The maintenance phase was extended for 10 months in cases of osteo-articular TB.

In the first group, dosages used were INH: $5(4-6) \mathrm{mg} /$ kg, RIF: 10 (8-12) mg/kg, PZA: 30-35 mg/kg, EMB: 20$25 \mathrm{mg} / \mathrm{kg}$ (Table 1) [21,22]. Fixed dose combinations (Isoniazid-50 mg, Rifampicin-100 mg, Pyrazinamide$300 \mathrm{mg}$ per dispersible tablet) and ethambutol $(200 \mathrm{mg})$ tablets were procured from Macleods Pharmaceuticals Limited, Mumbai, India.

In the second group, isoniazid and rifampicin were administered according to the revised dosage recommended by WHO- INH: 10 (7-15) mg/kg, RIF: 15 (1020) $\mathrm{mg} / \mathrm{kg}$, PZA: $30-35 \mathrm{mg} / \mathrm{kg}$, EMB: $20-25 \mathrm{mg} / \mathrm{kg}$ (Table 1) [12]. Fixed dose combinations (Isoniazid$75 \mathrm{mg}$, Rifampicin-100 mg, Pyrazinamide- $250 \mathrm{mg}$ per dispersible tablet, Concept Pharmaceutical Limited, India) were used along with separate tablets for ethambutol (200 mg), same as the first group (see Additional file 1 for tables describing the weight band based dosing for both groups of children).

Depending on their ability, children either swallowed the tablets with minimal water or the dispersible medicines were dissolved in a teaspoon of water and administered under supervision of study personnel.

\section{Blood sampling}

The samples for pharmacokinetic study were collected 14 days (upto 30 days) after starting ATT in all children. Pharmacokinetic sessions were planned such that the first sampling was done at least 24 hours from the last dose of ATT. On the day of scheduled blood sampling, enrolled children were asked to report in empty stomach in the morning to the pediatric services. The first blood sample (0 hour) was collected before administration of any drug. Immediately following the 0 hour sample, the medicines based on body weight measured at that point was administered. Next three point samplings at 1,2 and 4 hours were done, calculating from the time of intake of drugs. Breakfast was allowed one hour after the drug, after collecting the blood sample at that point. At each time point, $0.5 \mathrm{~mL}$ blood was collected in polypropylene tube wrapped in aluminum foil, containing EDTA and sodium ascorbate and kept at $4^{\circ} \mathrm{C}$. Plasma was separated soon after and stored at $-80^{\circ} \mathrm{C}$ till further analysis. The same schedule was followed in both the dosage groups.

\section{Measurement of anti-tubercular drug concentrations in plasma by liquid chromatography-mass spectrometry (LC-MS/MS)}

We used Ultra High Performance Liquid Chromatographic system (UHPLC, Thermo Surveyor system, CITY, USA) coupled with a triple quadrupole mass spectrometer,
API-4000 QTrap equipped with Turbo Ion Spray ionization (ESI) source (MDS SCIEX, Applied Biosystems, USA), operated in positive mode for separation and detection of analytes. Standards for isoniazid, rifampicin, pyrazinamide, ethambutol and 6- amino-nicotinic acid (6-ANA) were procured from Sigma-Aldrich Ltd, India, having purity greater than $99 \%$. Standard for acetyl isoniazid was synthesized inhouse [23]. Linear calibration curves for isoniazid, rifampicin, pyrazinamide, ethambutol and acetyl isoniazid were prepared separately, keeping $r>=0.99$. The LLOD (lower limit of detection) and LLOQ (lower limit of quantification) for each of the analytes were: $\mathrm{INH}=0.011 \mu \mathrm{g} / \mathrm{mL}$ and $0.014 \mu \mathrm{g} / \mathrm{mL}$, RIF $=0.025 \mu \mathrm{g} / \mathrm{mL}$ and $0.031 \mu \mathrm{g} / \mathrm{mL}, \mathrm{PZA}=$ $0.054 \mu \mathrm{g} / \mathrm{mL}$ and $0.547 \mu \mathrm{g} / \mathrm{mL}$, ETB $=0.015 \mu \mathrm{g} / \mathrm{mL}$ and $0.018 \mu \mathrm{g} / \mathrm{mL}$. Spiked sample calibration curve was subjected to inter-day and intraday variations' analysis. The calculated coefficient of variation for their inter-day and intraday variation was $<10 \%$.

\section{Pharmacokinetic parameters}

The pharmacokinetic parameters of $\mathrm{C}_{\max }$ (maximum plasma concentration achieved) and $\mathrm{T}_{\max }$ (time taken to achieve the maximum concentration) were determined by visual inspection of the data. Area under curve from 0-4 hours $\left(\mathrm{AUC}_{0-4}\right)$ was calculated by the linear trapezoidal rule. The actual values for plasma concentrations at various time points as determined by LCMS/MS assay were considered for analysis.

The lower cut-offs for acceptable two hour plasma concentration or the usually targeted concentrations in adults were as follows: Isoniazid $<3 \mu \mathrm{g} / \mathrm{mL}$, rifampicin $<8 \mu \mathrm{g} / \mathrm{mL}$, pyrazinamide $<20 \mu \mathrm{g} / \mathrm{mL}$ and ethambutol $<2 \mu \mathrm{g} / \mathrm{mL}$ [24].

Children with acetyl-isoniazid/isoniazid ratio at 4 hours of less than 1.0 were considered as slow acetylators [25].

\section{Follow-up}

The children were regularly followed-up till the completion of ATT and six months thereafter. Outcome of treatment was recorded in children for whom data for at least six months of ATT was available. Any child for whom change or extension of ATT regime was required or death occurred, was considered to be having a poor outcome. Good outcome was defined as completion of ATT within scheduled time. Any need for re-introduction of ATT after stopping therapy within the one year follow-up time period was defined as relapse. Category II ATT is defined as 2 months of INH + RIF+ EMB + PZA + injectable streptomycin, followed by one month of INH + RIF+ EMB + PZA, followed by 5 months of INH + RIF+ EMB [21].

\section{Sample size}

Considering the inadequacy of data from well-designed studies in children in context to influence of malnutrition on pharmacokinetics of anti-tubercular drugs, a 
sample size of thirty children in each group of children was considered sufficient.

\section{Statistical analysis}

Data were managed on MS Excel/Access softwares (version 2007) and analyzed using Stata 12.0 software (StataCorp, College Station, TX, USA). The significance of the differences in the categorical variables were assessed using chi-square or Fisher's exact test and that of continuous variables using student's $t$ test/Wilcoxon ranksum test as appropriate. A multivariate linear regression was done to predict the factors affecting 2 hour INH concentration, $\mathrm{C}_{\max }$ and $\mathrm{AUC}_{0-4}$ of INH and RIF, with dose of INH and RIF in $\mathrm{mg} / \mathrm{kg}$, age, gender, weight for age and height for age $\mathrm{z}$ score as covariates. In case of $\mathrm{INH}$, acetylator status was also included in the model.

A bivariate analysis (Wilcoxon ranksum test was used for the continuous variables, as the distribution was nonnormal, whereas for categorical variables, chi-squared test was used) was carried out to identify the factors influencing the outcome of ATT in the enrolled children for whom follow-up data of at least six months were available. A multivariate logistic regression model was used to predict the factors affecting outcome with 2-hour plasma concentration of INH, RIF, PZA and EMB, age, weight for age and height for age $\mathrm{z}$ score and BCG vaccination status as covariates.

Weight-for-age (WAZ), height-for-age (HAZ) and weight-for-height (WHZ) Z scores and BMI z scores were calculated using the nutritional anthropometry module of EpiInfo version 5 (Centers for Disease Control and Prevention, Atlanta), based on the CDC-2000 curves [18].

\section{Results}

We enrolled 127 children- 64 received the standard dose of ATT, whereas 63 received the revised dosage. The baseline characteristics of the enrolled children are outlined in Table 2. The children receiving standard or revised dosage of ATT were comparable in their baseline characteristics like age, gender, weight for height or BMI z-scores. All the children received category I ATT. Due to inadequate volume, one sample at 1 hour, 2 samples each at 2 and 4 hour time-points could not be assayed.

\section{Isoniazid}

The median $\mathrm{C}_{\max }$ and 2-hour levels, which were below usually targeted concentrations with the initial doses,

Table 2 Baseline characteristics of children receiving standard and revised dosage of anti-tubercular therapy

\begin{tabular}{|c|c|c|c|c|}
\hline \multirow[t]{2}{*}{ Characteristics } & \multicolumn{2}{|c|}{ Standard dosage, $\mathrm{n}=64$} & \multicolumn{2}{|l|}{ Revised dosage, $n=63$} \\
\hline & $\begin{array}{l}\text { Without severe } \\
\text { malnutrition, } n=32\end{array}$ & $\begin{array}{l}\text { With severe } \\
\text { malnutrition, } n=32\end{array}$ & $\begin{array}{l}\text { Without severe } \\
\text { malnutrition, } n=37\end{array}$ & $\begin{array}{l}\text { With severe } \\
\text { malnutrition, } n=26\end{array}$ \\
\hline Age, mean (SD), months & $97.2(43.9)$ & $105.9(43.1)$ & $126.5(28.4)$ & $91.3(38.6)$ \\
\hline \multicolumn{5}{|l|}{ No of children, n (\%) } \\
\hline$<2$ years of age & $1(3.1)$ & 0 & $1(2.7)$ & $1(3.8)$ \\
\hline $2-5$ years & $6(18.8)$ & $1(3.1)$ & $9(24.3)$ & $2(7.7)$ \\
\hline$>5$ years & $25(78.1)$ & $31(96.9)$ & $27(73)$ & $23(88.5)$ \\
\hline Boys, n (\%) & $15(46.9)$ & $15(46.9)$ & $20(54.1)$ & $16(61.5)$ \\
\hline Received BCG, n (\%) & $27(84.4)$ & $21(65.6)$ & $24(77.4)$ & $20(86.9)$ \\
\hline $\begin{array}{l}\text { Weight for age z score, } \\
\text { median (IQR) }\end{array}$ & $-1.5(-2.1,-0.7)$ & $-2.7(-3.2,-1.8)$ & $-1.3(-1.7,-0.4)$ & $-1.9(-2.4,-1.4)$ \\
\hline $\begin{array}{l}\text { Height for age z score, } \\
\text { median (IQR) }\end{array}$ & $-1.4(-2.03,0)$ & $-2.5(-4.2,-1.6)$ & $-1.1(-1.9,-0.1)$ & $-1.3(-2.1,-0.7)$ \\
\hline $\begin{array}{l}\text { Weight for height z score, } \\
\text { median (IQR) }\end{array}$ & $-1.1(-1.9,-0.7)$ & $-1.5(-1.9,-1.03)$ & $-0.6(-1.1,-0.2)$ & $-1.9(-2.2,-1.3)$ \\
\hline BMI z score, median (IQR) & $-0.8(-1.4,-0.2)$ & $-1.7(-2.5,-0.6)$ & $-0.7(-1.2,-0.4)$ & $-2.1(-2.8,-1.8)$ \\
\hline AFB/MGIT positive, $n$ (\%) & $5(15.6)$ & $9(28.1)$ & $6(16.2)$ & $7(26.9)$ \\
\hline \multicolumn{5}{|l|}{ Diagnosis, n (\%) } \\
\hline $\begin{array}{l}\text { Progressive pulmonary } \\
\text { disease }\end{array}$ & $18(56.2)$ & $18(56.2)$ & $11(29.7)$ & $16(61.5)$ \\
\hline Pleural effusion & $4(12.5)$ & $4(12.5)$ & $2(5.4)$ & 0 \\
\hline Disseminated & $10(31.3)$ & $10(31.3)$ & $3(8.1)$ & 0 \\
\hline Osteoarticular & 0 & 0 & $8(21.6)$ & $3(11.5)$ \\
\hline Peripheral lymphadenopathy & 0 & 0 & $13(35.2)$ & $7(27)$ \\
\hline
\end{tabular}

IQR: interquartile range, SD: standard deviation, AFB: acid fast bacillus, MGIT: Mycobacterial growth indicator tube, BCG: Bacillus Calmette Guerin. 
increased significantly after increasing the dose. The number of children with low 2-hour plasma concentrations was $59(95.2 \%)$ for the standard dose group as compared to $43(68.3 \%)$ for the revised dose group, $\mathrm{p}<$ 0.001 (Table 3). In the group with revised higher dose, the median $\mathrm{C}_{\max }$ achieved was significantly higher in children $<5$ years of age $[4.8(3.8,5.8)$ vs. $3.04(1.6,4.6)$ $\mu \mathrm{g} / \mathrm{mL}, \mathrm{p}=0.03]$, whereas no such age wise difference could be ascertained at a dose of $5 \mathrm{mg} / \mathrm{kg}$. The mean (SD) dose of INH in children younger than 5 years in the revised doses group was $12.1(0.8) \mathrm{mg} / \mathrm{kg}$ and 11.2 (0.7) $\mathrm{mg} / \mathrm{kg}$ for older children.

\section{Acetylator status}

The acetylator phenotype was determined in 122 children. Fast acetylator phenotype was ascertained in $81.2 \%$ of the children, whereas $18.8 \%$ were slow acetylators. In the group of children receiving standard dosage, $86.7 \%$ (52 children) were fast acetylators and 13.3\% (8 children) were slow acetylators; amongst the severely malnourished children in this group 90\% (27 children) were fast acetylators, whereas amongst the children who were not severely malnourished $83.3 \%$ were fast acetylators. In the other group receiving revised dosage, $75.8 \%$ (47 children) were fast acetylators whereas $24.2 \%$ ( 15 children) were slow acetylators; percentages of fast acetylators amongst children with or without severe malnutrition in this group were $84.6 \%$ and $69.4 \%$, respectively. In the first group, the median 2-hour plasma concentration [1.2 $(0.6,2.9)$ vs. $0.4(0.1,0.7) \mu \mathrm{g} / \mathrm{mL}, \mathrm{p}=0.001]$ as well as $C_{\max }$ achieved $[1.8(1.4,3.4)$ vs. $0.6(0.3,0.9) \mu \mathrm{g} / \mathrm{mL}$, $\mathrm{p}=0.0001]$ were higher in slow acetylators as compared to the fast acetylators. $\mathrm{AUC}_{0-4}$ obtained was also higher in the slow acetylators $[4.5(3.2,9.7) v s .1 .2(0.7,2.1) \mu \mathrm{g} /$ $\mathrm{mL}$ "hr, $\mathrm{p}=0.0001]$. Similarly in the revised doses group, slow acetylators attained a higher 2-hour concentration [3.8 (2.7, 5.1) vs. $1.6(1.1,2.9), \mathrm{p}=0.003]$ and $\mathrm{C}_{\max }[4.6$ $(3.4,7.2)$ vs. $2.9(1.5,4.7), \mathrm{p}=0.007]$ of INH as compared to the fast acetylators.
When a multivariate linear regression was done, only lower dose of INH in $\mathrm{mg} / \mathrm{kg}$ and fast acetylator status were significantly associated with lower 2-hour INH concentration, $\mathrm{C}_{\max }$ and $\mathrm{AUC}_{0-4}$ after adjusting for age, gender, weight for age and height for age $\mathrm{z}$ score.

\section{Rifampicin}

The median concentration reached at two hour timepoint and $\mathrm{C}_{\max }$ increased marginally with the increase in dose, the changes were not statistically significant. $\mathrm{AUC}_{0-4}$ also increased marginally $(\mathrm{p}=0.2)$. Number of children with low 2-hour plasma concentration remained almost unaltered $(43.5 \%$ vs. $41.3 \%, \mathrm{p}=0.8)$ (Table 3). There was no influence of age on the 2-hour concentration of RIF at either of the doses. A linear regression showed that lower 2-hour RIF concentrations, $C_{\max }$ and $\mathrm{AUC}_{0-4}$ were significantly associated with only dose in $\mathrm{mg} / \mathrm{kg}$ of RIF when adjusted for age, gender, weight for age and height for age $\mathrm{z}$ score.

\section{Pyrazinamide}

Dose of pyrazinamide above $30 \mathrm{mg} / \mathrm{kg}$ (mean: 35.8, SD: 3.6) resulted in plasma concentrations of the drug above the acceptable cut-off levels. Only eight (6.4\%) children had low 2-hour plasma levels (Table 4).

\section{Ethambutol}

More than half (55.9\%) of the children had 2-hour concentration lower than the usually targeted levels. Details are outlined in Table 4.

In the first group, 2-hour plasma concentrations of at least one drug were low in 59 (92.2\%) children. With the revised doses, 54 (85.7\%) children had low 2-hour plasma concentrations of at least one drug.

\section{Effect of nutritional status on pharmacokinetics of isoniazid, rifampicin, pyrazinamide and ethambutol} The pharmacokinetic parameters of isoniazid and rifampicin in either of the dosing schedules and that of

Table 3 Pharmacokinetic parameters of isoniazid and rifampicin at standard and revised dosage

\begin{tabular}{|c|c|c|c|c|c|c|}
\hline \multirow[t]{2}{*}{ Parameter } & \multicolumn{3}{|l|}{ Isoniazid } & \multicolumn{3}{|l|}{ Rifampicin } \\
\hline & Standard dose, $\mathrm{n}=64$ & Revised dose, $n=63$ & $p$ value & Standard dose, $\mathrm{n}=64$ & Revised dose, $n=63$ & $\mathrm{p}$ value \\
\hline Dose, mg/kg, mean (SD) & $5.6(0.5)$ & $11.4(0.8)$ & $<0.0001$ & $11.2(1.0)$ & $15.2(1.1)$ & $<0.0001$ \\
\hline $\begin{array}{l}\text { 2-hour concentration, } \\
\mu \mathrm{g} / \mathrm{mL}\end{array}$ & $0.4(0.2,0.8)$ & $2.0(1.2,3.7)$ & $<0.0001$ & $8.8(5.4,11.9)$ & $9.9(5.4,19.9)$ & 0.06 \\
\hline$C_{\max }, \mu g / m L$ & $0.7(0.3,1.2)$ & $3.4(1.8,5.0)$ & $<0.0001$ & $10.4(7.2,13.9)$ & $12.0(6.1,24.3)$ & 0.08 \\
\hline $\mathrm{T}_{\max }$, hour & $1(1,2)$ & $1(1,2)$ & 0.6 & $1.5(1,2)$ & $2(2,3)$ & 0.004 \\
\hline $\mathrm{AUC}_{0-4}, \mu \mathrm{g} / \mathrm{mL}^{*} \mathrm{hr}$ & $1.5(0.8,2.6)$ & $7.0(4.4,11.9)$ & $<0.0001$ & $28.0(19.3,35.5)$ & $30.5(17.1,58.9)$ & 0.2 \\
\hline $\begin{array}{l}\text { Low 2-hr concentration*, } \\
\text { n (\%) }\end{array}$ & $59(95.2)$ & $43(68.3)$ & $<0.001$ & $27(43.5)$ & $26(41.3)$ & 0.79 \\
\hline
\end{tabular}

Values are expressed as median (IQR) unless specified.

*Low 2-hr concentrations: plasma concentration of isoniazid $<3 \mu \mathrm{g} / \mathrm{mL}$, rifampicin $<8 \mu \mathrm{g} / \mathrm{mL}$ at 2 hour post drug time point.

$C_{\max }$ : maximum concentration, $\mathrm{T}_{\max }$ : Time needed to reach the maximum concentration, $\mathrm{AUC}$ : area under curve. 
Table 4 Pharmacokinetic parameters of ethambutol and pyrazinamide in 127 children

\begin{tabular}{|c|c|c|}
\hline Parameter & Ethambutol & Pyrazinamide \\
\hline Dose, mg/kg, mean (SD) & $21.7(2.4)$ & $35.7(3.6)$ \\
\hline 2-hour concentration, $\mu \mathrm{g} / \mathrm{mL}$ & $1.5(0.6,3.1)$ & $42.7(34.9,52.9)$ \\
\hline$C_{\max }, \mu \mathrm{g} / \mathrm{mL}$ & $2.1(1.0,3.7)$ & $47.8(39.4,58.5)$ \\
\hline$T_{\max }$, hours & $2(1,2)$ & $2(1,2)$ \\
\hline$A U C_{0-4}, \mu \mathrm{g} / \mathrm{mL}^{*} \mathrm{hr}$ & $4.8(2.2,8.9)$ & $140.5(117.4,173.2)$ \\
\hline Low 2-hr concentration*, n (\%) & $71(55.9)$ & $8(6.4)$ \\
\hline
\end{tabular}

Values are expressed as median (IQR) unless specified.

*Low 2-hr concentration: plasma concentration of ethambutol $<2 \mu \mathrm{g} / \mathrm{mL}$, pyrazinamide $<20 \mu \mathrm{g} / \mathrm{mL}$ at 2 hour post drug time point.

$C_{\text {max }}$ : maximum concentration, $T_{\max }$ : Time needed to reach the maximum concentration, AUC: area under curve.

pyrazinamide or ethambutol $\left(\mathrm{C}_{\max }, \mathrm{AUC}_{0-4}, \mathrm{~T}_{\max }\right)$ and number of children with low two hour plasma concentration did not differ in children with or without severe malnutrition (see Additional file 1).

\section{Treatment response}

Evaluation of treatment response at the end of six months of anti-tubercular therapy were available in 62 children of the first group and 61 children in the second group receiving revised dosage of ATT.

In the first group, category II ATT had to be started due to non-resolution of symptoms or radiological findings in $4(6.2 \%)$ children, 2nd line ATT was started in one $(1.6 \%)$ child. One (1.6\%) child had relapse of disease after completion of therapy and was administered category II treatment. Hepatitis developed in 2 (3.2\%) children. With the standard dosing schedule, nature of outcome was not associated with the plasma concentrations or $\mathrm{AUC}_{0-4}$ achieved for any of the four drugs studied. However, there was a trend of median (IQR) $\mathrm{C}_{\max }$ of INH being lower in children with poor outcome [1.3 $(0.7,1.5)$ vs. $3.4(1.8,5.0) \mu \mathrm{g} / \mathrm{mL}, \mathrm{p}=0.05]$.

Only confirmation of Mycobacterium tuberculosis was associated with the outcome, with children with poor outcome having a higher percentage of confirmed cases (55.6\% vs. $16.4 \%, \mathrm{p}=0.01$ ) (Table 5). A multivariate logistic regression model showed that there was no association of 2-hour plasma concentration of INH, RIF, PZA and EMB with poor outcome, when adjusted for age, weight for age and height for age $\mathrm{z}$ score and BCG vaccination status.

In the second group, three (4.9\%) children were administered category II ATT due to worsening or nonimprovement of symptoms, one (1.6\%) child had relapse of disease. There was only one death in a child with disseminated TB and severe malnutrition. Three (4.9\%) children had developed features of hepatitis in this group. Even with the increased dosage schedule, concentrations of the four drugs studied were not associated with the outcome of treatment. In this group, children with lower weight and BMI z score had poorer outcome (Table 5).

\section{Discussion}

The current study, conducted in 127 children with tuberculosis, observed that most of the children had low levels of at least one of the four drugs, the plasma levels of isoniazid and ethambutol were suboptimal in majority of children enrolled. With the revised dosage, concentrations of both isoniazid and rifampicin increased, though the change was not statistically significant in case of rifampicin. We did not observe an association between low plasma drug concentrations and poor outcome. There was no effect of malnutrition on 2-hour concentrations, $\mathrm{C}_{\max }, \mathrm{T}_{\max }$, and $\mathrm{AUC}_{0-4}$ of isoniazid, rifampicin, pyrazinamide and ethambutol in either of the two dosing schedules used.

Multiple time point sampling as in conventional pharmacokinetic studies is challenging in children as there are concerns regarding parental consent, ethical issues and collection of samples. A limited sampling approach at four time points was adopted in this study. This strategy had been validated for rifampicin in an earlier study from the same institute conducted in adults to study the absorption phase [26]. Though it was not possible to comment on parameters like halflife and volume of clearance, the absorption spectrum could be well studied.

The assays used for measurement of serum or plasma drug concentrations in the previous studies on pharmacokinetics of anti-tubercular drugs in children have been varied and hence, the comparison of results obtained is challenging. Of various assays to measure the plasma drug levels, LC-MS/MS is the most sophisticated and sensitive, only a few studies in children with tuberculosis have used this assay $[7,8]$. In the current study, the plasma concentrations of all the four first line anti-tubercular drugs were measured simultaneously by LC-MS/MS. This allowed a high throughput and sensitive assay.

The plasma levels of the anti-tubercular drugs have been evaluated both for intermittent dosing, $[10,16,27,28]$ and daily schedules $[7,8,29-31]$. There are differences in the formulations used in various studies. Some of the studies used individual, separate tablets for each drug studied, [16,30-32] while in many other studies fixed dose formulations of isoniazid, rifampicin and pyrazinamide were used $[7-9,29,33]$. The current study reports the pharmacokinetic details of isoniazid, rifampicin, pyrazinamide as well as ethambutol in Indian children, after daily dosing of the medicines using fixed dose formulations of isoniazid, rifampicin and pyrazinamide along with separate tablets of ethambutol. 
Table 5 Factors affecting outcome of therapy in children with at least six months of follow-up on ATT

\begin{tabular}{|c|c|c|c|c|c|c|}
\hline \multirow[b]{2}{*}{ Variables } & \multicolumn{3}{|c|}{ Standard dosage of ATT, $n=62$} & \multicolumn{3}{|c|}{ Revised dosage of ATT, $n=61$} \\
\hline & $\begin{array}{l}\text { Good outcome } \\
n=53\end{array}$ & $\begin{array}{l}\text { Poor outcome } \\
\mathrm{n}=9\end{array}$ & $p$ value & Good outcome $n=44$ & Poor outcome $n=17$ & $p$ value \\
\hline $\begin{array}{l}\text { 2-hr plasma isoniazid concentration, } \\
\mu \mathrm{g} / \mathrm{mL}\end{array}$ & $0.4(0.2,0.8)$ & $0.5(0.2,0.8)$ & 0.9 & $2.3(1.2,3.9)$ & $1.7(1.3,2.8)$ & 0.2 \\
\hline $\begin{array}{l}\text { 2-hr plasma rifampicin concentration, } \\
\mu \mathrm{g} / \mathrm{mL}\end{array}$ & $8.7(5.4,11.9)$ & $9.7(3.9,11.6)$ & 0.8 & $9.5(5.3,21.2)$ & $11.3(5.7,15.2)$ & 0.9 \\
\hline $\begin{array}{l}\text { 2-hr pyrazinamide concentration, } \\
\mu \mathrm{g} / \mathrm{mL}\end{array}$ & $40.4(34.8,46.9)$ & $44.2(38.4,53.1)$ & 0.7 & $39.8(35.0,44.7)$ & $41.4(34.4,47.8)$ & 0.8 \\
\hline $\begin{array}{l}\text { 2-hr ethambutol concentration, } \\
\mu \mathrm{g} / \mathrm{mL}\end{array}$ & $0.7(0.4,1.5)$ & $0.6(0.5,0.9)$ & 0.4 & $2.5(1.7,3.7)$ & $3.2(2.2,4.8)$ & 0.2 \\
\hline$C_{\max }$ isoniazid, $\mu \mathrm{g} / \mathrm{mL}$ & $3.4(1.8,5.0)$ & $1.3(0.7,1.5)$ & 0.05 & $3.2(2.0,4.7)$ & $3.5(1.8,5.2)$ & 0.6 \\
\hline $\mathrm{C}_{\max }$ rifampicin, $\mu \mathrm{g} / \mathrm{mL}$ & $10.3(6.8,13.9)$ & $11.5(7.8,14.3)$ & 0.9 & $10.4(7.7,14.0)$ & $12.8(6.6,15.3)$ & 0.5 \\
\hline$C_{\max }$ pyrazinamide, $\mu \mathrm{g} / \mathrm{mL}$ & $50.1(39.2,67.5)$ & $52.8(43.5,68.5)$ & 0.8 & $46.7(40.4,52.6)$ & $43.4(38.4,53.9)$ & 0.5 \\
\hline$C_{\max }$ ethambutol, $\mu \mathrm{g} / \mathrm{mL}$ & $1.1(0.7,2.1)$ & $1.2(0.5,1.9)$ & 0.8 & $3.3(2.3,4.1)$ & $3.7(2.3,4.9)$ & 0.4 \\
\hline $\mathrm{AUC}_{0-4}$ isoniazid, $\mu \mathrm{g} / \mathrm{mL}^{*} \mathrm{hr}$ & $1.3(0.7,2.4)$ & $1.9(1.5,3.3)$ & 0.2 & $7.9(4.2,13.2)$ & $5.9(4.5,10.1)$ & 0.3 \\
\hline $\mathrm{AUC}_{0-4}$ rifampicin, $\mu \mathrm{g} / \mathrm{mL}^{*} \mathrm{hr}$ & $27.9(19.1,36.1)$ & $30.2(23.5,34.1)$ & 0.8 & $25.3(16.6,60.7)$ & $30.6(21.7,44.1)$ & 0.8 \\
\hline $\mathrm{AUC}_{0-4}$ pyrazinamide, $\mu \mathrm{g} / \mathrm{mL}^{*} \mathrm{hr}$ & $159.9(111.8,207.0)$ & $155.3(125.3,210.9)$ & 0.9 & $137.8(123.6,158.3)$ & $133.7(121.4,151.6)$ & 0.5 \\
\hline $\mathrm{AUC}_{0-4}$ ethambutol, $\mu \mathrm{g} / \mathrm{mL} \mathrm{L}^{*} \mathrm{hr}$ & $2.5(1.5,5.5)$ & $2.1(1.4,3.7)$ & 0.5 & $7.7(4.9,10.7)$ & $10.0(5.9,10.9)$ & 0.5 \\
\hline WAZ at baseline & $-1.8(-2.8,-1.1)$ & $-1.9(-3.2,-1.7)$ & 0.3 & $-1.3(-1.9,-0.6)$ & $-1.9(-2.3,-1.8)$ & 0.007 \\
\hline HAZ at baseline & $-1.5(-2.1,-0.2)$ & $-1.2(-1.9,-0.2)$ & 0.8 & $-1.1(-2.3,-0.2)$ & $-1.5(-1.9,-0.8)$ & 0.5 \\
\hline Received BCG, n (\%) & $42(76.4)$ & $6(66.7)$ & 0.7 & $31(70.4)$ & $11(64.7)$ & 0.7 \\
\hline Mycobacterium confirmed, n (\%) & $9(16.4)$ & $5(55.6)$ & 0.01 & $8(18.6)$ & $4(23.5)$ & 0.7 \\
\hline Diagnosis, n (\%) & & & 0.9 & & & 0.5 \\
\hline Progressive pulmonary disease & $30(56.6)$ & $5(55.6)$ & & 17 (38.6) & $10(58.8)$ & \\
\hline Pleural effusion & $7(13.2)$ & $1(11.1)$ & & $1(2.3)$ & $1(5.9)$ & \\
\hline Disseminated & $16(30.2)$ & $3(33.3)$ & & $2(4.5)$ & $1(5.9)$ & \\
\hline Osteoarticular & 0 & 0 & & $9(20.5)$ & $2(11.8)$ & \\
\hline Peripheral lymphadenopathy & 0 & 0 & & $15(34.1)$ & $3(17.6)$ & \\
\hline
\end{tabular}

Values are median (IQR) unless specified, AUC: area under curve, WAZ: weight for age z score, HAZ: height for age z score, BCG: Bacillus Calmette-Guérin, IQR: interquartile range, $C_{\text {max }}$ : maximum concentration.

\section{Isoniazid}

Several studies have reported low 2-hour concentration or low $\mathrm{C}_{\max }$ of isoniazid in large proportion of children with doses of around $5 \mathrm{mg} / \mathrm{kg} /$ day, though not in the proportions observed in the current study. In earlier studies up to $83 \%$ children have been reported to have a suboptimal plasma concentration of isoniazid. $[8,29]$ While some authors have reported low levels in only 12 $14 \%$ of children studied [16,34].

Thee et al. reported low $\mathrm{C}_{\max }$ in half of the children following a dose of $5 \mathrm{mg} / \mathrm{kg}$ of isoniazid, but in none after dose of $10 \mathrm{mg} / \mathrm{kg}$ in children younger than two years [33]. Recent simulation studies have showed that higher doses lead to increased $\mathrm{C}_{\max }$ and isoniazid exposure $[35,36]$. A study on 20 low birth weight infants demonstrated that though adequate $\mathrm{C}_{\max }$ was achieved at a dose of $10 \mathrm{mg} / \mathrm{kg} \mathrm{INH}$, elimination was reduced in younger and smaller infants, thus raising a note of caution against using higher doses in this age group [37].
Our study showed a significantly higher increase in $\mathrm{C}_{\max }$ and $\mathrm{AUC}_{0-4}$ in younger children (less than five years), when the revised doses were used. Hence the impact of increasing the dose may be different in children according to age groups and should be taken into account while hiking the INH doses.

Acetylator status predicted the isoniazid exposure in our cohort of children, fast acetylators having a lower 2hour level, $\mathrm{C}_{\max }$ and $\mathrm{AUC}_{0-4}$. This corroborates with the findings of other researchers who also observed an association of lower isoniazid concentrations with fast acetylator phenotype $[6,8]$. Acetylation status varies according to the ethnicity of populations. India has a population of diverse gene pool varying with geographical regions [38]. There have been dissimilar reports from different parts of India on the acetylator status of Indian population, determined phenotypically and genotypically. Studies from south India have established a predominance of slow acetylators up to $74 \%$ of the population [39]. A 
recent study by Ramachandran found 32\% fast acetylators in south Indian children, determined by estimation of salivary INH levels [16]. However other studies from north Indian adult population have reported lower proportion of slow acetylators, [40-42] ranging from $14.5 \%$ to $35.4 \%$. The distribution of acetylator phenotype in the current study, with $81.2 \%$ fast acetylators, matches that of north Indian population. Since acetylator status is an important factor in the plasma concentration of INH achieved by a person, intra and inter population differences will have an impact on determining the doses needed for a particular population and the guidelines issued by any program.

Increasing the dose has significantly improved the plasma concentrations in our study, providing supportive evidence to the revised dosing schedule of WHO. But the number of children with low two hour levels still remain unacceptably high (68.2\%), factors other than just increasing the dose must be sought to explain this. Also some caution and more studies may be warranted while using the higher dose in younger children, as shown in our study that younger children may achieve better plasma concentrations of the drug. Recent WHO guidelines have recommended isoniazid in the range of $7-15 \mathrm{mg} / \mathrm{kg}$ mainly to facilitate ease of administration with the currently available FDCs [43].

\section{Rifampicin}

Several studies have raised concern regarding inadequate exposure of rifampicin after a dose of around $10 \mathrm{mg} / \mathrm{kg}$. Seth et al. demonstrated a $C_{\max }$ of $3.3-3.8 \mu \mathrm{g} / \mathrm{mL}$ after an average dose of $12 \mathrm{mg} / \mathrm{kg}$ of rifampicin [44]. In recent studies with doses of around $10 \mathrm{mg} / \mathrm{kg}$ up to $90 \%$ children had sub-therapeutic maximum concentrations of rifampicin [7,16,29].

Using the revised WHO dosing schedule, Thee et al. demonstrated that $C_{\max }$ and AUC were significantly augmented when dose of rifampicin was increased from 10 to $15 \mathrm{mg} / \mathrm{kg}$. A dose of $15 \mathrm{mg} / \mathrm{kg}$ led to only three out of eleven children having suboptimal peak concentration of rifampicin [33]. In our study the concentrations of rifampicin did increase with dose, but not significantly, neither did the number of children with low two hour levels vary. Inspite of initial concerns, studies have now documented that the bioavailability from fixed dose combinations and single, separate formulations are equivalent [45]. Hence, the use of fixed dose combinations in our study, may not have contributed substantially to the low levels of concerned drugs. Again there may be other factors like malabsorption, drug-interactions, efflux proteins, contributing to the low levels other than just inadequate dose.

\section{Pyrazinamide}

There have been few reports in children regarding low levels of pyrazinamide. Approximately one-thirds of children receiving $30-33 \mathrm{mg} / \mathrm{kg}$ of pyrazinamide have been reported to have low peak concentrations $[9,10,16$, $29,30,46]$.

Our study demonstrated that concentrations achieved by administering pyrazinamide above $30 \mathrm{mg} / \mathrm{kg}$ were adequate and very few children had inadequate 2-hour levels of pyrazinamide.

\section{Ethambutol}

Data regarding pharmacokinetics of ethambutol in children is limited globally. Various authors have reported low levels of plasma ethambutol concentrations $[10,47,48]$, the average doses ranged from $15 \mathrm{mg} / \mathrm{kg}$ to $25 \mathrm{mg} / \mathrm{kg}$. In view of more than half (55.9\%) of the children in our study having low 2-hour levels of ethambutol at a mean dose of $21.7 \mathrm{mg} / \mathrm{kg}$, consideration may be given to increasing the dose, albeit keeping in mind the possible toxicities. However, additional pharmacokinetic studies are needed to garner further evidence before any suggestions can be made.

\section{Effect of malnutrition}

In our study, we did not observe any effect of malnutrition on 2 hour concentrations, $\mathrm{C}_{\max }, \mathrm{T}_{\max }$, and $\mathrm{AUC}_{0-4}$ of isoniazid, rifampicin, pyrazinamide or ethambutol, even with enhanced dosing. There are contrasting reports of influence of nutritional status on exposure of anti-tubercular drugs in children. Some earlier studies on isoniazid and rifampicin reported that serum concentrations of these drugs were higher in malnourished children [49].

Other studies in children with poor nutritional status have suggested that bioavailability of anti-tubercular drugs, especially rifampicin and pyrazinamide is lower in malnutrition $[16,50]$. On the other hand, similar to our results, few studies have reported absence of effect of malnutrition on pharmacokinetics of anti- tubercular drug levels [8,10,27,33,51,52].

There are various pathophysiological changes associated with malnutrition which may affect different aspects of drug pharmacokinetics, it is difficult to predict the result of interplay of the various effects. This study and the previous studies have estimated the total plasma concentrations; it may be worthwhile to determine the free drug concentrations in plasma as well as the intracellular drug concentrations, the latter may particularly be relevant as the pathogen is intracellular.

\section{Correlation with treatment response}

The outcome of tuberculosis in this cohort of children was not influenced by the levels of anti-tubercular drugs studied. However, there was a trend of median $\mathrm{C}_{\max }$ of INH being lower in children with poor outcome at the dose of $5 \mathrm{mg} / \mathrm{kg}$. The cut off levels for optimal plasma 
concentrations of anti-tubercular drugs have been derived from adult healthy volunteers studied under controlled environment and validated at National Jewish Medical and Research Center by Peloquin et al. [24]. These two hour cut-off values have since been widely used worldwide by various researchers. But the optimal concentrations required for effective therapy and hence, cure of tuberculosis in children are not exactly known as there are very few studies which have tried to associate dose and serum concentrations of anti-tubercular drugs with successful outcome of therapy.

In a study on Indian children on intermittent ATT, unfavorable treatment outcome was found to be associated with lower isoniazid and rifampicin exposure [16]. A South African study primarily designed to assess the difference in serum concentration of rifampicin in HIV infected and uninfected children, demonstrated no association between weight gain or chest X-ray clearance and any of the pharmacokinetic parameters of rifampicin [7]. In addition to the drug concentrations, the body's immune system is likely to play a major role in tackling the tuberculosis disease. Also the drugs have to target the mycobacteria, most of which are intracellular, it may be important to study the intracellular drug concentrations as well. Synergistic action of pyrazinamide with rifampicin, isoniazid with ethambutol may compensate for the low levels of one drug [53]. This may explain the observation of acceptable outcomes in a scenario where most of the anti-tubercular drugs showed low levels of anti-tubercular drugs. However, there may be an effect on long-term likelihoods of relapse; this aspect has not been studied.

Interestingly, proportion of unfavourable outcome was higher in children receiving the increased doses of ATT. This group had higher numbers of children with extrapulmonary disease and had lower weight-for-age $\mathrm{Z}$ scores than the group receiving lower doses; these may have affected the response to therapy.

Strengths of this study include the use of a highly sensitive assay for simultaneously estimating the plasma concentrations of all 4 first line anti-tubercular drugs in children. We have assessed the drug levels after modifying the doses of isoniazid and rifampicin. The present study also described the pharmacokinetics of ethambutol in Indian children for which data are not available in published literature. Also the revised dosages of isoniazid and rifampicin have been evaluated in the Indian children for the first time, enabling us to assess the efficacy of this regimen. We have also reported outcomes in the enrolled children.

The limitations of the study include the inability to evaluate pharmacokinetic details like half-life, rate of clearance, due to the truncated sampling strategy followed and use of 2-hour plasma concentration as a measure of optimal dose. The limited numbers of children in each of the treatment sub-groups complicates the assessment of association of outcome with plasma concentrations of the drugs.

\section{Conclusion}

The results of this study have led credence to the concern that doses used in children were inadequate leading to inadequate plasma concentrations of isoniazid, rifampicin and ethambutol. Increasing the dose of isoniazid seems to have beneficial effects on plasma concentration achieved. But augmenting the dose of rifampicin has failed to significantly alter the concentrations achieved or number of children with low two hour levels. Malnutrition was not associated with low plasma concentrations of any of these drugs. No relationship was found between drug concentration and treatment response, even in augmented doses. We may have to be cautious while increasing the doses and strive to asses any other factors which may be influencing the drug concentrations and treatment outcomes in children.

\section{Additional file}

Additional file 1: Table S1: Weight band based dosage of fixed dose combination of isoniazid, rifampicin and pyrazinamide and ethambutol tablets in the first group of standard dosage schedule. Table S2: Weight band based dosage of fixed dose combination of isoniazid, rifampicin and pyrazinamide and ethambutol tablets in the second group of revised dosage schedule. Table S3: Effect of malnutrition on the pharmacokinetic parameters of isoniazid at different dosages. Table S4: Effect of malnutrition on the pharmacokinetic parameters of rifampicin at different dosages. Table S5: Effect of malnutrition on the pharmacokinetic parameters of pyrazinamide and ethambutol.

\section{Abbreviations}

ATT: Anti-tubercular therapy; BMI: Body mass index; EMB: Ethambutol; HAZ: Height for age z score; INH: Isoniazid; LC-MS/MS: Liquid chromatographymass spectrometry; PZA: Pyrazinamide; RIF: Rifampicin; RNTCP: Revised National Tuberculosis Control Program; TB: Tuberculosis; WAZ: Weight for age z score; WHO: World Health Organization; WHZ: Weight for age z score.

\section{Competing interests}

The author(s) declare that they have no competing interests.

\section{Authors' contributions}

AM participated in conceptualization and conduct of study, analyzing of data and writing of manuscript; TV participated in conceptualization and conduct of study, and writing of manuscript; MS and KK participated in conduct of study; SKK and RL participated in conceptualization of study, analyzing of data and writing of manuscript. All authors read and approved the final manuscript.

\section{Acknowledgement}

The research staff of the pediatrics pulmonary unit and Ocular Pharmacology department of AllMS, New Delhi, India.

\section{Funding}

This work was partly supported by Indian Council of Medical Research, India. 


\section{Author details}

${ }^{1}$ Department of Pediatrics, All India Institute of Medical Sciences, New Delhi, India. ${ }^{2}$ Department of Ocular Pharmacology, All India Institute of Medical Sciences, New Delhi, India.

\section{Received: 5 November 2014 Accepted: 2 March 2015} Published online: 14 March 2015

\section{References}

1. World Health Organization. Global tuberculosis report. Geneva, Switzerland: World Health Organization; 2013

2. Weiner M, Benator D, Burman W, Peloquin CA, Khan A, Vernon A. Association between acquired rifamycin resistance and the pharmacokinetics of rifabutin and isoniazid among patients with HIV and tuberculosis. Clin Infect Dis. 2005;40:1481-91.

3. Weiner M, Burman W, Vernon A, Benator D, Peloquin CA, Khan A. Low isoniazid concentrations and outcome of tuberculosis treatment with once-weekly isoniazid and rifapentine. Am J RespirCrit Care Med. 2003;167:1341-7.

4. Morehead RS. Delayed death from pulmonary tuberculosis: unsuspected subtherapeutic drug levels. South Med J. 2000;93:507-10

5. Mehta JB, Shantaveerapa H, Byrd Jr RP, Morton SE, Fountain F, Roy TM Utility of rifampin blood levels in the treatment and follow-up of active pulmonary tuberculosis in patients who were slow to respond to routine directly observed therapy. Chest. 2001;120:1520-4.

6. Schaaf HS, Parkin DP, Seifart HI, Werely CJ, Hesseling PB, Van Helden PD. Isoniazid pharmacokinetics in children treated for respiratory tuberculosis. Arch Dis Child. 2005:90:614-8.

7. Schaaf HS, Willemse M, Cilliers K, Labadarios D, Maritz JS, Hussey GD Rifampin pharmacokinetics in children, with and without human immunodeficiency virus infection, hospitalized for the management of severe forms of tuberculosis. BMC Med. 2009;7:19.

8. Mcllleron H, Willemse M, Werely CJ, Hussey GD, Schaaf HS, Smith PJ. Isoniazid plasma concentrations in a cohort of South African children with tuberculosis: implications for international pediatric dosing guidelines. Clin Infect Dis. 2009;48:1547-53.

9. Mcllleron H, Willemse M, Schaaf HS, Smith PJ, Donald PR. Pyrazinamide plasma concentrations in young children with tuberculosis. Pediatr Infect Dis J. 2011;30:262-5.

10. Graham SM, Bell DJ, Nyirongo S, Hartkoorn R, Ward SA, Molyneux EM. Low levels of pyrazinamide and ethambutol in children with tuberculosis and impact of age, nutritional status, and human immunodeficiency virus infection. Antimicrob Agents Chemother. 2006;50:407-13.

11. World Health Organization. Report of the meeting on TB medicines for children. Geneva, Switzerland: WHO; 2008.

12. World Health Organization. Rapid Advice Treatment of tuberculosis in children. Geneva, Switzerland: WHO, Geneva, Switzerland; 2010.

13. Oshikoya KA, Sammons HM, Choonara I. A systematic review of pharmacokinetics studies in children with protein-energy malnutrition. Eur J ClinPharmacol. 2010;66:1025-35.

14. Oshikoya KA, Senbanjo IO. Pathophysiological changes that affect drug disposition in protein-energy malnourished children. Nutr Metab. 2009;6:50.

15. Mehta S. Drug disposition in children with protein energy malnutrition. J Pediatr Gastroenterol Nutr. 1983;2:407-17.

16. Ramachandran G, Hemanth Kumar AK, Bhavani PK, Poorana Gangadevi N, Sekar L. Age, nutritional status and INH acetylator status affect pharmacokinetics of anti-tuberculosis drugs in children. Int J Tuberc Lung Dis. 2013;17:800-6.

17. Kumar A, Gupta D, Nagaraja SB, Singh V, Sethi GR, Prasad J, et al. Updated current (2012) national guidelines for paediatric tuberculosis in India. J Indian Med Assoc. 2012;110(11):840-5.

18. Centers for Disease Control and Prevention. Growth Charts - 2000 CDC Growth Charts. CDC.gov. 2013. Available from: http://www.cdc.gov/growthcharts/cdc_charts.htm, Accessed on: 10th Aug, 2014.

19. World Health Organization. Management of severe malnutrition: a Manual for Physicians and Other Senior Health Workers. Geneva, Switzerland: WHO; 1999.

20. Chauhan LS, Arora VK. Management of pediatric tuberculosis under the Revised National Tuberculosis Control Program (RNTCP). Indian Pediatr. 2004:41:901-5

21. Kabra SK, Lodha R, Seth V. Category based treatment of tuberculosis in children Indian Pediatr 2004:41:927-37.
22. World Health Organization. Guidance for National Tuberculosis Programmes on the management of tuberculosis in children. Geneva, Switzerland: World Health Organization; 2006.

23. Olson WA, Dayton PG, Israili ZH, Pruitt AW. Spectrophotofluorometric assay for isoniazid and acetyl isoniazid in plasma adapted to pediatric studies. Clin Chem. 1977;23:745-8.

24. Peloquin CA. Therapeutic drug monitoring in the treatment of tuberculosis. Drugs. 2002;62:2169-83.

25. Smith CA, Wadelius M, Gough AC, Harrison DJ, Wolf CR, Rane A. A simplified assay for the arylamine $\mathrm{N}$-acetyltransferase 2 polymorphism validated by phenotyping with isoniazid. J Med Genet. 1997;34:758-60.

26. Prakash J, Velpandian T, Pande JN, Gupta SK. Serum rifampicin levels in patients with tuberculosis : Effect of P-Glycoprotein and CYP3A4 blockers on its absorption. Clin Drug Investig. 2003;23:463-72.

27. Roy V, Gupta D, Gupta P, Sethi GR, Mishra TK. Pharmacokinetics of isoniazid in moderately malnourished children with tuberculosis. Int J Tuberc Lung Dis. 2010;14:374-6.

28. Seth V, Seth SD, Beotra A, Semwal OP, D'monty V, Mukhopadhya S. Isoniazid and acetylisoniazid kinetics in serum and urine in pulmonary primary complex with intermittent regimen. Indian Pediatr. 1994;31:279-85.

29. Verhagen LM, López D, Hermans PWM, Warris A, De Groot R, Garcia JF. Pharmacokinetics of anti-tuberculosis drugs in Venezuelan children younger than 16 years of age: supportive evidence for the implementation of revised WHO dosing recommendations. Trop Med Int. 2012;17:1449-56.

30. Arya DS, Ojha SK, Semwal OP, Nandave M. Pharmacokinetics of pyrazinamide in children with primary progressive disease of lungs. Indian J Med Res. 2008;128:611-5.

31. Roy V, Tekur U, Chopra K. Pharmacokinetics of isoniazid in pulmonary tuberculosis-a comparative study at two dose levels. Indian Pediatr. 1996:33:287-91.

32. Roy $V$, Tekur U, Chopra K. Pharmacokinetics of pyrazinamide in children suffering from pulmonary tuberculosis. Int J Tuberc Lung Dis. 1999:3:133-7.

33. Thee S, Seddon JA, Donald PR, Seifart HI, Werely CJ, Hesseling AC. Pharmacokinetics of isoniazid, rifampin, and pyrazinamide in children younger than two years of age with tuberculosis: evidence for implementation of revised World Health Organization recommendations. Antimicrob Agents Chemother. 2011;55:5560-7.

34. Ibrahim M, Engidawork E, Yimer G, Bobosha K. Pharmacokinetics of isoniazid in Ethiopian children with tuberculosis in relation to the $\mathrm{N}$-acetyltransferase 2 (NAT2) genotype. Afr J Pharm Pharmacol. 2013;7:1124-30.

35. Kiser JJ, Zhu R, D'Argenio DZ, Cotton MF, Bobat R, McSherry GD. Isoniazid pharmacokinetics, pharmacodynamics, and dosing in South African infants. Ther Drug Monit. 2012;34:446-51.

36. Zvada SP, Denti P, Donald PR, Schaaf HS, Thee S, Seddon JA. Population pharmacokinetics of rifampicin, pyrazinamide and isoniazid in children with tuberculosis: in silico evaluation of currently recommended doses. J Antimicrob Chemother. 2014;69:1339-49.

37. Bekker A, Schaaf HS, Seifart HI, Draper HR, Werely CJ, Cotton MF. Pharmacokinetics of isoniazid in low-birth-weight and premature infants. Antimicrob Agents Chemother. 2014;58:2229-34.

38. Narang A, Roy RD, Chaurasia A, Mukhopadhyay A, Mukerji M, Dash D Indian Genome Variation Consortium, et al. IGVBrowser-a genomic variation resource from diverse Indian populations. Database 2010. doi:10.1093/ database/baq022.

39. Anitha A, Banerjee M. Arylamine N-acetyltransferase 2 polymorphism in the ethnic populations of South India. Int J Mol Med. 2003;11:125-31.

40. Gupta RC, Nair CR, Jindal SK, Malik SK. Incidence of isoniazid acetylation phenotypes in North Indians. Int J Clin Pharmacol. 1984;22:259-64.

41. Rana SV, Ola RP, Sharma SK, Arora SK, Sinha SK, Pandhi P, et al. Comparison between acetylator phenotype and genotype polymorphism of n-acetyltransferase-2 in tuberculosis patients. Hepatol Int. 2011;6(1):397-408.

42. Srivastava DSL, Mittal RD. Genetic polymorphism of the N-acetyltransferase 2 gene, and susceptibility to prostate cancer: a pilot study in north Indian population. BMC Urol. 2005:5:12.

43. World Health Organization. Guidance for national tuberculosis programmes on the management of tuberculosis in children. Geneva, Switzerland: WHO; 2014.

44. Seth V, Beotra A, Seth SD, Semwal OP, Kabra S, Jain Y. Serum concentrations of rifampicin and isoniazid in tuberculosis. Indian Pediatr. 1993;30:1091-8.

45. Agrawal S, Singh I, Kaur KJ, Bhade SR, Kaul CL, Panchagnula R. Comparative bioavailability of rifampicin, isoniazid and pyrazinamide from a four drug 
fixed dose combination with separate formulations at the same dose levels. Int J Pharm. 2004;276:41-9.

46. Roy V, Sahni P, Gupta P, Sethi GR, Khanna A. Blood levels of pyrazinamide in children at doses administered under the Revised National Tuberculosis Control Program. Indian Pediatr. 2012;49:721-5.

47. Zhu M, Burman WJ, Starke JR, Stambaugh JJ, Steiner P, Bulpitt AE. Pharmacokinetics of ethambutol in children and adults with tuberculosis Int J Tuberc Lung Dis. 2004;8:1360-7.

48. Thee S, Detjen A, Quarcoo D, Wahn U, Magdorf K. Ethambutol in paediatric tuberculosis: aspects of ethambutol serum concentration, efficacy and toxicity in children. Int J Tuberc Lung Dis. 2007;11:965-71.

49. Seth V, Beotra A, Bagga A, Seth S. Drug therapy in malnutrition. Indian Pediatr. 1992:29:1341-6.

50. Akbani Y, Bolme P, Lindblad BS, Rahimtoola RJ. Control of streptomycin and isoniazid in malnourished children treated for tuberculosis. ActaPaediatrScand. 1977;66:237-40.

51. Seifart HI, Donald PR, De Villiers JN, Parkin DP, Jaarsveld PP. Isoniazid elimination kinetics in children with protein-energy malnutrition treated for tuberculous meningitis with a four-component antimicrobial regimen. Ann Trop Paediatr. 1995;15:249-54.

52. Eriksson M, Bolme P, Habte D, Paalzow L. INH and streptomycin in Ethiopian children with tuberculosis and different nutritional status. Acta Paediatr Scand. 1988;77:890-4.

53. Dickinson JM, Aber VR, Mitchison DA. Bactericidal activity of streptomycin, isoniazid, rifampin, ethambutol, and pyrazinamide alone and in combination against Mycobacterium Tuberculosis. Am Rev Respir Dis. 1977;116:627-35.

\section{Submit your next manuscript to BioMed Central and take full advantage of:}

- Convenient online submission

- Thorough peer review

- No space constraints or color figure charges

- Immediate publication on acceptance

- Inclusion in PubMed, CAS, Scopus and Google Scholar

- Research which is freely available for redistribution 